\title{
CLASSIFICAÇÃO ECOLÓGICA DAS ESPÉCIES ARBÓREAS
}

\author{
Ecological classification of arboreal species
}

\author{
Maria de Nazaré Martins Maciel" \\ Luciano Farinha Watzlawick" \\ Emerson Roberto Schoeninger \\ Fabio Minoru Yamaji
}

\section{Resumo}

O presente trabalho teve como objetivo efetuar um levantamento sobre as classificações ecológicas de espécie arbóreas. Uma breve abordagem foi sintetizada sobre o processo de dinâmica sucessional em floresta tropical e dos principais elementos que caracterizam esse processo. Também foi mostrado a existência da grande diversidade de classificações das espécies em grupos ecológicos.

Palavras-chave: Sucessão, Grupos ecológicos, Clímax.

\section{Abstract}

The present work had as objective to effect a survey on the ecological classifications of tree species. Thus, a brief explanation was made about succession dynamics process of tropical forest and about main elements that characterize this process. Also the existence of the great diversity of classifications of the species in ecological groups was shown.

Keywords: Succession, Ecological groups, Climax.

* Pesquisadora do Departamento de Ciências Florestais, Faculdade de Ciências Agrárias do Pará, e-mail: nmaciel@ig.com.br .

** Professor Substituto, Departamento de Ciências Florestais, Universidade Federal do Paraná, e-mail: luciano_farinha@uol.com.br

*** Doutorando, Programa de Pós-Graduação em Engenharia Florestal, Universidade Federal do Paraná, e-mail: emer@floresta.ufpr.br

***** Doutorando, Programa de Pós-Graduação em Engenharia Florestal, Universidade Federal do Paraná, e-mail: fmyamaji@floresta.ufpr.br 


\section{Introdução}

A grande biomassa lenhosa que constitui as florestas tropicais nativas é um recurso natural, cujo aproveitamento, em bases sustentáveis, ainda desafia a ciência florestal, porque representa um ecossistema complexo, cujo equilíbrio pode ser facilmente rompido se houver uma perturbação tão intensa, a ponto de causar modificações irreversíveis.

Deve-se considerar que as florestas tropicais nativas podem ser manejadas para a produção de madeira, para fins industriais e energéticos específicos, para a produção de serviços e benefícios diretos e indiretos, e para a produção de outras matérias-primas e produtos não-madeireiros. Entretanto, os vários sistemas silviculturais, aplicados ao manejo da floresta tropical, que objetivam o rendimento sustentável, ainda exigem conhecimentos básicos sobre a dinâmica de crescimento e recomposição da floresta nativa original, para que possam ser aplicados com sucesso, sem comprometer a estabilidade e a sustentabilidade desse recurso e dos elementos essenciais à vida na terra.

Para que se possa promover o aproveitamento sustentável das florestas tropicais, é necessário conhecer como elas renovam seus recursos, os processos de dinâmica da regeneração natural e seu potencial qualitativo e quantitativo.

Existe consenso que os processos de dinâmica de sucessão natural das florestas tropicais dependem, fundamentalmente, da formação de clareiras por morte ou queda natural de árvores. Portanto, qualquer que seja o sistema de manejo que se pretende desenvolver para esse tipo de floresta, ele deverá, forçosamente, levar em consideração o processo de dinâmica de sucessão natural em clareiras. Assim, com base na literatura disponível, elaborou-se o presente trabalho, objetivando o estudo das diferentes classificações ecológicas de espécies arbóreas em resposta aos distúrbios naturais ou intervenções antrópicas na floresta tropical.

\section{A classificação ecológica de espécies arbóreas}

As espécies de plantas tropicais têm sido classificadas de diversas maneiras quanto ao seu comportamento na dinâmica de sucessão. A dinâ- mica sucessional na floresta, como um todo, pode ser representada por um processo continuo de abertura-recobrimento-fechamento-abertura de clareiras (BARTON, 1984). Para efeito didático, entretanto, considera-se que este processo se inicia com a abertura de uma clareira, que é uma descontinuidade, de tamanhos variados, que se projeta do dossel até o solo da floresta, provocada principalmente pela queda de um galho de uma ou várias árvores.

\section{Conceito}

Para que se possa ter um maior entendimento do processo dinâmico da sucessão natural nas clareiras, é necessário que se apresente uma definição prévia dos elementos que o caracterizam.

Sucessão: Segundo Dajoz (1983), as sucessões podem ser primárias ou secundárias. A sucessão primária corresponde ao estabelecimento dos seres em um meio, onde ainda não haviam povoado, mas no qual foram eliminados, por vários motivos, os seres ali anteriormente viventes. Gomes-Pompa (1972) define sucessão secundária como as mudanças que se verificam nos ecossistemas, após a destruição parcial de uma comunidade, podendo ocorrer em uma pequena área de floresta nativa, após a queda de uma árvore, ou em vários hectares de uma cultura abandonada.

Para Richards (1952), esse processo é representado pela progressiva mudança na composição florística da floresta, desde as espécies secundárias (pioneiras) até as espécies primárias (clí$\max )$.

Tracey (1985) define sucessão secundária como o processo que envolve várias combinações de estádios florísticos pioneiros, secundários iniciais e secundários tardios, antes que um estádio maduro da floresta seja restituído.

Clareira: O conceito de clareira "gap" é bastante variado na literatura. Oldeman (1978) utiliza o termo "chablis" para designar tanto a queda de uma árvore como a perturbação que lhe é associada.

Bazzaz; Pickett (1980) definem clareira como brechas no dossel da floresta, cujas condições ambientais diferem daquelas do dossel fe- 
chado e cujos recursos, particularmente luz, deixam de ser controlados pelos indivíduos do dossel dominante.

Para Almeida (1989), clareira é toda a área de floresta com dossel descontínuo, aberto pela queda de galhos de uma ou mais árvores, limitada pela copa das árvores marginais.

A definição apresentada por Bazzaz; Pickett (1980) parece ser a mais consistente, pois além de caracterizar a clareira como uma abertura em formas geométricas -"brechas", dá idéia do caráter funcional desse espaço no processo sucessional.

\section{As clareiras como matrizes de sucessão}

Segundo Whitmore (1978), uma floresta é um mosaico de manchas em diferentes estádios de maturidade, cujo ciclo de crescimento inicia com uma clareira. O autor acrescenta que, para muitas espécies, um dos principais fatores que regulam a estrutura da população é a chance de ocorrência de uma clareira sobre as plântulas, a qual lhes permita crescer. Mesmo buracos no dossel, que permitam não mais de 40 minutos diários de insolação, podem estimular o crescimento de plântulas no solo da floresta (SCHULZ, 1960). Em relação a floresta tropical amazônica, Uhl; Murphy (1981) mencionam a existência de um banco de plântulas e mudas por longos períodos, à espera de um distúrbio que favoreça seu crescimento. Sem isso, todas as plântulas, exceto aquelas espécies do subbosque, que gastam toda a sua vida em densa sombra, eventualmente morrerão (WHITMORE, 1978). Esse autor divide o processo sucessional em três fases:

Fase de clareira - compreende o início da recomposição florestal, com grande número de plântulas provenientes da germinação de sementes já existentes no solo ou que chegam de fora, após a abertura da clareira ou da regeneração preestabelecida no sub-bosque (WHITMORE, 1984; HUBBELL; FÖSTER, 1986, citados por ALMEIDA, 1989).

Fase de edificação - inclui indivíduos delgados (varas) em intenso crescimento em altura. Nessa fase, ocorrem fortes competições entre os indivíduos e morte de certas espécies pionei- ras, alternadas com períodos de homeostase, conforme Hallé et al. (1978), citados por Almeida (1989).

Fase madura - a maioria dos indivíduos chega à fase reprodutiva, estando a floresta em equilíbrio dinâmico e a biomassa tendendo a se estabilizar na capacidade produtiva do ecossistema (clímax). Nesta fase, há predomínio do crescimento diamétrico, com a expansão lateral das copas (WHITMORE, 1984; BROKAW, 1985 citado por ALMEIDA, 1989).

Ainda, segundo Whitmore (1978), essas fases são abstrações, e não entidades separadas. Efetivamente, no desenvolvimento da sucessão em uma clareira existe um gradiente contínuo, cuja característica instantânea é determinada, principalmente, pela idade da clareira, mas que pode ser influenciada por fatores como a composição florística inicial da comunidade e eventos biológicos (frutificação e dispersão) e físicos (queda de novas árvores), após a abertura inicial. Na fase de clareira, as mudas não excedem $2,70 \mathrm{~m}$; na fase de edificação, não existem grandes árvores; e na fase madura, todos os tamanhos estão misturados (UHL e MURPHY, 1981).

Para Barton (1984), as clareiras representam o principal fator de coexistência de muitas espécies de árvores nas florestas tropicais. Além disso, quando a floresta envelhece, sua suscetibilidade aos distúrbios muda. Árvores velhas são, freqüentemente, mais propensas a rupturas ou tombamentos, originando grandes clareiras. Assim, em florestas velhas, espécies pioneiras e de grandes clareiras podem novamente aumentar em número ou densidade.

\section{Características das clareiras}

De acordo com Whitmore (1978), as clareiras são formadas por um rompimento na estrutura do dossel da floresta. Isso pode ser causado pela queda de uma ou várias árvores, que caem pela ação de fatores, como ventos fortes, temporais e raios. Segundo Whitmore (1978) e Bazzaz e Picket (1980), a queda pode, ainda, ser provocada por grandes distúrbios naturais, como ciclones e terremotos. Orians (1982) sugere, também, como fatores que determinam a formação de clareiras, a predominância de raízes superficiais e o grande 
número de cipós e epífitas que crescem sobre a copa das árvores, aumentando significativamente o peso que deve ser suportado pelas raízes.

Tamanho: Segundo Whitmore (1978), as mais diminutas clareiras são formadas pela morte lenta de uma árvore, cuja copa e fuste caem verticalmente em pedaços. Clareiras também podem ser formadas pela queda de várias árvores, entrelaçadas por cipós (ORIANS, 1982), ou pelo chamado efeito dominó, em que uma árvore ao cair, derruba outras. Dessa forma, existe uma amplitude muito grande de tamanhos de clareiras, embora a maior freqüência esteja nas classes de tamanho menores que $100 \mathrm{~m}^{\prime \prime}$, como demonstra Brokaw (1982).

Diferentes espécies são bem sucedidas em clareiras de diferentes tamanhos, significando que o tamanho da clareira influencia fortemente a composição florística e a distribuição espacial das espécies na floresta (WHITMORE, 1978; SILVA, 1989). Quanto maior a clareira, mais diferente o microclima dentro dela, em relação ao da floresta não perturbada (WHITMORE, 1978). Portanto, segundo Hartshorn (1978), o tamanho da clareira pode determinar quais espécies colonizam ou não uma clareira, porque ele causa importantes mudanças no microclima e na competição de raízes, competição esta que pode diminuir temporariamente no centro da clareira. Segundo Bazzaz e Picket (1980), pequenas clareiras favorecem o crescimento de regeneração avançada, como é o caso de plântulas e mudas já estabelecidas antes da formação da clareira. Por outro lado, em clareiras muito grandes, esses indivíduos podem crescer pouco ou mesmo morrer em virtude de alta carga de radiação solar (WHITMORE, 1978).

Ambiente Físico : Segundo Bazzaz e Picket (1980), clareiras são ambientes heterogêneos, com um complexo gradiente que se estende do centro delas até às condições inalteradas sob o dossel.

Para Whitmore (1978), as principais diferenças entre o ambiente na clareira e sob o dossel fechado são um aumento na luz e mudanças na sua qualidade, aumento em temperatura e um déficit de saturação. Há, também, um aumento nos nutrientes quando as plantas mortas são decompostas. Essas mudanças no meio físico alteram o meio biológico, pois mudas estabelecidas morrem por causa de sua sensibilidade à luz, plantas de espécie pioneiras aparecem e outras têm uma maximização de crescimento (VIEIRA e HIGUCHI, 1990).

\section{Divisão das espécies em grupos ecológicos}

A vegetação de um local é formada por um componente real e por um componente potencial. O primeiro é representado por indivíduos de espécies presentes e o segundo, por sementes e propágulos existentes no solo. O banco de sementes conserva-se no solo, sem germinar, em razão de fatores bióticos (inibidores químicos, período de latência, atividades de microorganismos, etc.) e de fatores abióticos (luz, temperatura, umidade, etc.). Esse banco de sementes, assim como sua viabilidade e latência, condiciona o potencial florístico (HASPER et al., 1965), que é formado por espécies de etapas sucessionais anteriores e espécies que não tinham estado presentes na área e que fazem parte do potencial, graças à sua capacidade de dispersão. GOMEZ-POMPA et al. (1972) observaram que grande proporção de espécie, secundárias, está na forma de sementes no solo florestal.

As plantas secundárias são heliófilas, de rápido crescimento, possuem sementes de grande viabilidade e têm mecanismo de dispersão muito eficiente, aparecendo, logo em seguida, às perturbações no ambiente (SMITH, 1966, citado por Gomez-Pompa et al. 1976). Além disso, produzem maior quantidade de sementes (HARTSHORN, 1978).

O recurso principal na determinação do comportamento das espécies, na dinâmica de sucessão, é a luz. Baseado nisso, têm surgido diversas classificações de grupos ecológicas de espécies arbóreas tropicais.

Whitmore (1984) reconhece quatro grupos de espécies relativos à demanda por clareiras:

- Espécies que se estabelecem e crescem sob dossel fechado;

- Espécies que se estabelecem e crescem sob dossel fechado, mas que se beneficiam das clareiras;

- Espécies que se estabelecem e crescem sob dossel fechado, mas que requerem clareiras para amadurecer e se reproduzir; e 
- Espécies que se estabelecem, crescem e se reproduzem somente em clareiras.

Entretanto, o autor reconhece que estes são apenas pontos no amplo gradiente de condições, demandado pelas espécies e que cada espécie pode ser única em suas exigências.

Já Swaine e Hall (1983) classificaram as espécies em três categorias:

- Espécies pioneiras pequenas, que requerem uma clareira para germinação e estabelecimento. São de vida relativamente curta e raramente atingem 30 metros de altura;

- Espécies pioneiras grandes, que requerem uma clareira para germinar e estabelecimento. São capazes de exceder 30 metros de altura e persistem até formar o dossel da floresta madura;

- Espécies primárias, capazes de germinar e se estabelecer pelo menos em luz difusa, persistindo até formar o dossel da floresta madura.

Por outro lado, Viana (1989) apresentou uma classificação em que constam quatro categorias:

- Heliófilas, cujas sementes requerem clareiras para germinar, e as plântulas não sobrevivem sob sombra;

- Oportunistas de clareiras, cujas sementes não precisam de clareiras para germinar, e as plântulas sobrevivem apenas na sombra;

- Tolerantes à sombra, cujas sementes germinam à sombra e as plântulas crescem só até o estádio pré-reprodutivo; e

- Reprodutoras em sombra, cujas sementes germinam à sombra reproduzindo-se nela e os indivíduos reproduzidos vivem nesta condição.

Finegam (1992) classificou as espécies florestais em quatro grupos ecológicos:

Espécies heliófilas efêmeras, cujas características principais são: as abertas;

- Rápida colonização e ocupação de áre-

- Produção de grande quantidade de sementes em idade precoce;

- Sementes com capacidade de mante- rem-se viáveis por longo tempo no solo da floresta;

- Alta capacidade fotossintética sob luz direta;

- Rápido crescimento;

- Madeira leve e de pouca resistência;

- Regeneram e completam o seu ciclo da vida somente em áreas abertas, relativamente extensas;

- Ciclo de vida curto, variando entre 1015 anos, podendo chegar a 35-40 em condições favoráveis.

Dentre as principais espécies deste grupo estão: Cecropia spp., Heliocarpus sp. e Trema sp.

Espécies heliófilas duráveis, cujas características ecológicas principais são:

- Dominam o povoamento depois que as efêmeras desaparecem, e permanecem por muito tempo;

- Capacidade fotossintética intermediária sob luz direta;

- Rápido crescimento, com incrementos diamétricos de até $2-3 \mathrm{~cm}$ ano;

- Madeira moderadamente leve a moderadamente pesada.

- Reprodução precoce em condições favoráveis;

- Sementes variam em tamanho, entre pequenas e médias, com disseminação feita principalmente pelo vento e com menor durabilidade no banco de sementes;

- As plântulas podem sobreviver até por um ano ou mais à sombra e respondem positivamente quando se abre o dossel;

- São capazes de se estabelecer em clareiras relativamente pequenas dentro da floresta primária, das quais as heliófilas efêmeras são excluídas.

Dentre as principais espécies deste grupo encontra-se: Cedrela odorata, Ceiba pentandra, Swietenia sp., Eucaliptus deglupta, Gmelina arbórea, Pinus caribaea, além de gêneros Qualea e Vochysia.

\section{Espécies esciófitas parciais}

Estas espécies toleram a sombra nas etapas iniciais de seu desenvolvimento, porém, re- 
querem um elevado grau de iluminação para passar pelas etapas intermediárias até a maturidade, aumentando o seu crescimento se ocorrer uma abertura no dossel, ou seja, toleram sombra, mas não a requerem.

Neste grupo, encontram-se as espécies: Carapa guianensis, Lecythis spp., Pentaclethra macroloba, além do gênero Virola.

\section{Espécies esciófitas totais}

Este grupo representa uma proporção muito reduzida da flora arbórea tropical. São espécies que requerem sombra e não têm a capacidade de aumentar significativamente seu crescimento com a abertura do dossel. Seu aparato fotossintético se satura a níveis relativamente baixos de iluminação. Neste grupo, encontram-se as espécies: Minquartia guianensis e as espécies do gênero Pouteria.

Denslow (1980) identifica três grandes grupos na sucessão. O primeiro formado por especialistas de grandes clareiras, cujas sementes germinam somente sob condições de alta temperatura e/ou luminosidade, com plântulas totalmente intolerantes à sombra. As espécies, do segundo e terceiro grupo, têm germinação de sementes e o estabelecimento de plântulas sob a sombra e constituem as especialistas de sub-bosque, correspondendo, de certo modo, às secundárias e às clímaces. Enquanto as plântulas das espécies de pequenas clareiras exigem abertura do dossel para crescerem, as de sub-bosque necessitam da clareira.

Swaine e Whitmore (1988) definem dois grupos ecológicos de espécies em floresta tropical úmida:

\section{Espécies pioneiras:}

- Espécies cujas sementes só germinam em clareiras, em dossel completamente aberto, recebendo radiação direta em pelo menos parte do dia. Entre as espécies deste grupo encontramse: Solanum spp., Cecropia spp., Goupia glabra, Laetia procera, Cedrela odorata, Eucalyptus deglupta.

\section{Espécies não pioneiras ou clímaces:}

- Espécies cujas sementes podem germinar sob sombra. As plântulas são encontradas sob o dossel, mas podem também ser encontradas em ambientes abertos. Fazem parte deste grupo as espécies Courati spp., Vochysia máxima, Eschweilera spp., Minquara guianensis e Coussarea spp.

Whitmore (1990) mostrou a classificação pioneira/clímax com base em 16 características das espécies tropicais (Tabela 1).

Para Rollet (1978) a análise da distribuição diamétrica de uma espécie dá uma informação preliminar do caráter dessa espécie, com relação à luz. Espécies tolerantes são aquelas com distribuição diamétrica na forma exponencial negativa (j invertido). Espécies com distribuição errática, com ausência de indivíduos nas classes menores são chamadas de pioneiras, fortemente heliófilas. Espécies com comportamentos intermediários entre esses extremos são chamadas de oportunistas, podendo ser de grande ou de pequenas clareiras, conforme sejam mais ou menos heliófilas.

Budowski (1965) com base em vinte e uma características das espécies que compõe o ecossistema de florestas tropicais propôs classificálas em pioneiras, secundárias iniciais, secundárias tardias e clímaces (tabela 2). As espécies pioneiras teriam um papel de recobrir rapidamente o solo; as clímaces cresceriam à sombra das pioneiras; e as secundárias necessitariam de um estímulo para crescer ou de um tutoramento. 
TABELA 1 - Características contrastantes de dois grupos ecológicos de espécies tropicais Table 1- Specific characteristics of two ecological groups of tropical species

\begin{tabular}{|c|c|c|}
\hline Sinônimos & $\begin{array}{l}\text { Intolera ntes, demandantes de luz, } \\
\text { pioneiras, espécies secundárias. }\end{array}$ & $\begin{array}{l}\text { Tolerantes, resistentes a sombra, } \\
\text { clímax, espécies primárias. }\end{array}$ \\
\hline Sementes & $\begin{array}{l}\text { Abundantes, pequenas, produção contínua } \\
\text { durante todo o ano }\end{array}$ & Pouco abundantes, grande produção anual \\
\hline Dispersão & $\begin{array}{c}\text { Vento ou animais, por distâncias } \\
\text { consideráveis }\end{array}$ & $\begin{array}{c}\text { Diversas, inclusive gravidade, às vezes } \\
\text { somente no local }\end{array}$ \\
\hline Dormência & Quase sempre presente, nunca recalcitrante & $\begin{array}{c}\text { Quase sempre ausente, quase sempre } \\
\text { recalcitrante }\end{array}$ \\
\hline Banco de sementes & Presente & Ausente \\
\hline Crescimento em altura & Rápido & Lento \\
\hline Madeira & Geralmente clara, baix a densidade, sem sílica & $\begin{array}{l}\text { Normalmente escura, alta densidade, às } \\
\text { vezes com sílica }\end{array}$ \\
\hline Crescimento & Indeterminado & Determinado \\
\hline Bifurcação & Alta & Baixa \\
\hline Folhas & Vida curta & Vida longa \\
\hline Raízes & Superficiais & Algumas profundas \\
\hline Taxa de mortalidade/rai z & Baixa & Alta \\
\hline Taxa fotossintética & Alta & Baixa \\
\hline Toxidade química & Baixa & Alta \\
\hline $\begin{array}{l}\text { Susceptibilidade às } \\
\text { folhas predação }\end{array}$ & Alta & Baixa \\
\hline Distribuição geográfica & Ampla & Geralmente restrita \\
\hline Plasticidade fenotípica & Alta & Baixa \\
\hline
\end{tabular}

Fonte: Whitmore (1990) 
TABELA 2 - Características dos componentes arbóreos do estágio geral em florestas tropicais Table 2 - Characteristics of tree components of the general canopy in tropical forests

\begin{tabular}{|c|c|c|c|c|}
\hline & Pioneiras & Secundárias iniciais & Secundárias tardias & Clímaces \\
\hline $\begin{array}{l}\text { Idades das } \\
\text { comunidades } \\
\text { estudadas (ano) }\end{array}$ & $1-3$ & $5-15$ & $20-50$ & Acima de 100 \\
\hline Altura (m) & $5-8$ & $12-20$ & $20-30$ & $30-45$ \\
\hline $\begin{array}{l}\text { N.. o de espécies } \\
\text { madeireiras }\end{array}$ & $1-5$ & $1-10$ & $30-60$ & Acima de 100 \\
\hline Composição florística & $\begin{array}{c}\text { Euphorbiacea, } \\
\text { Cecropia, Ochroma, } \\
\text { Trema } \\
\end{array}$ & $\begin{array}{l}\text { Cecropia, Ochroma, } \\
\text { Trema, Heliocarpus }\end{array}$ & $\begin{array}{c}\text { Misturada predominando } \\
\text { Meliaceae, Bombacaceae e } \\
\text { Tiliaceae } \\
\end{array}$ & Misturada \\
\hline Distribuição natural & Muito ampla & Muito ampla & Ampla & Restrita \\
\hline Número de estratos & Um, muito denso & $\begin{array}{c}\text { Dois, bem } \\
\text { diferenciados }\end{array}$ & $\begin{array}{c}\text { Três, facilit ando a } \\
\text { diferenciação com o tempo }\end{array}$ & $\begin{array}{c}\text { Quatro a } \\
\text { cinco, difícil } \\
\text { de diferenciar }\end{array}$ \\
\hline Dossel & Homogêneo, denso & $\begin{array}{c}\text { Ramos verticulados, } \\
\text { copas finas e } \\
\text { horizontais }\end{array}$ & Heterogêneo & $\begin{array}{c}\text { Formas das } \\
\text { copas muito } \\
\text { variáveis }\end{array}$ \\
\hline Estrato inferior & Denso, emaranhado & $\begin{array}{l}\text { Denso, muito } \\
\text { herbáceos }\end{array}$ & Relativamente raro & $\begin{array}{l}\text { Raros, com } \\
\text { espécies } \\
\text { tolerantes }\end{array}$ \\
\hline Crescimento & Muito rápido & Muito rápido & Rápido, outros lentos & $\begin{array}{c}\text { Lento ou } \\
\text { muito lento }\end{array}$ \\
\hline Longe vidade & $\begin{array}{l}\text { Muito curta, abaixo } \\
\text { de } 10 \text { anos }\end{array}$ & Curta de 10-25 anos & $\begin{array}{l}\text { Normalmente entre 40-100 } \\
\text { anos }\end{array}$ & $\begin{array}{c}\text { Muito longa } \\
\text { de } 100 \text { a } 1000 \\
\text { anos } \\
\end{array}$ \\
\hline Tolerância à sombra & Muito intolerante & Muito intolerante & $\begin{array}{l}\text { Tole rante no estágio juvenil, } \\
\text { depois intolerante }\end{array}$ & $\begin{array}{l}\text { Tolerante, } \\
\text { exceto no } \\
\text { está gio adulto }\end{array}$ \\
\hline Regeneração & Muito rara & Praticamente ausente & $\begin{array}{c}\text { Ausente ou abundante, com } \\
\text { grande mortalidade nos } \\
\text { primeiros anos }\end{array}$ & Abundante \\
\hline $\begin{array}{l}\text { Disseminação de } \\
\text { sementes }\end{array}$ & $\begin{array}{l}\text { Pássaros, morcegos e } \\
\text { vent o }\end{array}$ & $\begin{array}{l}\text { Páss aros, morcego e } \\
\text { vent o }\end{array}$ & Principalmente pelo vento & $\begin{array}{l}\text { Gravidade, } \\
\text { pássaros, } \\
\text { roedores e } \\
\text { mamíferos }\end{array}$ \\
\hline Madeira e fuste & $\begin{array}{l}\text { Muito leve, pequeno } \\
\text { diâmetro }\end{array}$ & $\begin{array}{l}\text { Muito leve, diâmetro } \\
\text { abaixo de } 60 \mathrm{~cm}\end{array}$ & $\begin{array}{c}\text { Leve a mediamente pesadas, } \\
\text { às vezes, fustes muitos } \\
\text { grossos } \\
\end{array}$ & $\begin{array}{c}\text { Pesados, } \\
\text { fustes grossos }\end{array}$ \\
\hline $\begin{array}{l}\text { Tamanho das } \\
\text { sementes }\end{array}$ & Pequenas & Pequenas & Pequenas a médias & Grandes \\
\hline $\begin{array}{l}\text { Viabilidade de } \\
\text { sementes }\end{array}$ & $\begin{array}{l}\text { Longa, latente no } \\
\text { solo sempre verdes }\end{array}$ & $\begin{array}{l}\text { Longa, latente no } \\
\text { solo }\end{array}$ & Curta à media & Curta \\
\hline Folhas & Sempre verdes & Sempre verdes & Muitas decíduas & Sempre verdes \\
\hline Epífitas & Ausente & Poucos & $\begin{array}{l}\text { Muito em número, pouco em } \\
\text { espécies }\end{array}$ & $\begin{array}{l}\text { Muitas } \\
\text { espécies e } \\
\text { formas de } \\
\text { vida }\end{array}$ \\
\hline Cipós & $\begin{array}{c}\text { Abundante, } \\
\text { herbáceos }\end{array}$ & $\begin{array}{c}\text { Abundantes, } \\
\text { herbáceos }\end{array}$ & $\begin{array}{c}\text { Abundantes, alguns } \\
\text { compridos } \\
\end{array}$ & $\begin{array}{c}\text { Abundantes, } \\
\text { compridos }\end{array}$ \\
\hline Arbustos & $\begin{array}{l}\text { Muitos, mas poucas } \\
\text { espécies }\end{array}$ & $\begin{array}{l}\text { Relativamente } \\
\text { abundantes, mas } \\
\text { poucas espécies }\end{array}$ & Poucos & $\begin{array}{l}\text { Pouco em } \\
\text { número, mas } \\
\text { muito em } \\
\text { espécie. }\end{array}$ \\
\hline Gramíneas & Abundante & Abundante ou rara & Rara & Rara \\
\hline
\end{tabular}

Fonte: Budowski (1965). 


\section{Conclusão}

O estudo da classificação ecológica, de espécies arbóreas, deu condições de ampliação de conhecimentos sobre o complexo processo de sucessão natural em florestas tropicais, permitindo concluir que:

- Processo sucessional em florestas tropicais úmidas depende, fundamentalmente, da formação de clareiras, o que torna mais intensa a chegada de luz até o solo da floresta;

- A luz que chega no interior da clareira depende de sua forma, tamanho e localização e a grande diversidade da floresta tropical é conseqüência da adaptação das espécies a esse gradiente de condições luminosas;

- As classificações ecológicas feitas pelos diversos autores representam uma simplificação muito grande dentro do amplo gradiente de comportamento das espécies de florestas tropicais, portanto, não é possível adotá-las como padrão;

- O conhecimento da dinâmica sucessional dessas florestas é fundamental na solução de problemas, como a manutenção da riqueza de espécies e o desenvolvimento de sistemas silviculturais, visando seu manejo sustentável.

\section{Referências}

ALMEIDA, S. S. Clareiras naturais na Amazônia Central: abundância, distribuição, estrutura e aspectos da colonização vegetal. Manaus, INPA, 1989. $125 \mathrm{p}$.

BARTON, A. M. Neotropical pioneer and shade tolerant tree species: do they partition tree fall gaps?. Tropical Ecology, (25) :196-202, 1984.

BAZZAZ, E'. A. Dynamics of wet tropical forest and their species strategies. In: MEDINA, MOONEY; VASQUES-YANES.C. Physiological ecology of plants of the wet tropics. The Hague, 1984. p.233-243.

BAZZAZ, E. A.; PICKETT, S. T. A. Physiological ecology of tropical succession: A comparative review. Ann. Rev. Ecol. Syst., (11) 287-310, 1980.

BROKAW, N. V. L. Definition of tree fall gap and its effect on measures of forest dynamics. Biotropica, 14(12): 158-60, 1982.
BUDOWSKI, G. N. Distribution of tropical American rain forest species in the light of succession processes. Turrialba, 15 (1) 40-2, 1965.

DAJOZ, R. Ecologia geral. Rio de Janeiro, Vozes, 1983. 472p.

DENSLOW, J. W. Gap partitioning among tropical rain forest trees. Biotropica, 12: 47-55, 1980.

FINEGAN, B. Bases ecológicas de la silvicultura y la agroforesteria. Turrialba - Costa Rica, Centro Agronômico Tropical de Investigacion y Ensenanza - CATIE, 1992. 153 p.

GOMEZ-POMPA, A.; VASQIJES-YANES, C.; AMO RODRIGUE3, 3.; CERVERA, A. B. Investigaciones sobre la regeneración de las selvas altas en Veracruz, Mexico. Mexico, Continental, 1976. 676 p.

GOMEZ-POMPA, A.; VASQIJES, C., GIJEVARA, 3. The tropical rain forest: a non-renewable resource. Science, (177) :762-5, 1972.

HARTSHORN, C. Tree falls and tropical forest dynamics. In: TOMLINSON, Z. Tropical trees as living systems. London, Cambridge Univ. Press., 1978. p. 617-638.

HASPER, J. L., WILLIAMS, T.J., SAGAR, G. R. The behavior of seeds in the soil. The heterogeneity off soil surfaces and its role in determining the establishment of plants from seeds. J. Ecology, (53) :273-86, 1965.

OLDEMAN, R. A. A. Architecture and energy exchange of dicotyledoneous trees in forest. In: TOMLINSON, Z. Tropical trees as living systems. London, Cambridge Univ. Press., 1978. p. $535-60$

ORIANS, G. E. The influence of tree-falls in tropical forests in tree species richness. Tropical Ecology, 23 (2): 255-79, 1982.

PICKETT, S.T.A. Differential adaptation off tropical trees species to canopy gaps and its role in community dynamics. Tropical Ecology, 24 (1) :6884, 1983.

RICEARDS, P. LV. The tropical rain forest. Cambridge, Cambridge Univ. Press, 1952. 450 p.

ROLLET, B. Arquitetura e crescimento das florestas tropicais. s.1., s.ed., 1978. 30p. 
SCHULZ, J. P. Ecological studies on rain forest in Northern Surinam. Amsterdam, North Holland, 1960. 267 p.

SILVA, J. N. M. The behavior of the Tropical Rain Forest of the Brazilian Amazon after logging. Oxford, Oxford University, 1989. 325 p.

SWAINE, M. D.; EALL, J.B. Early succession on cleared forest land in Ghana. J. Ecology, (71) : 601-27, 1983.

SWAINE, M. IX ; LVEITMORE, T. C. On definition of ecological species groups in tropical rain forests. Vegetation, (75) 81-86, 1988.

TRACEY, J. G. A note on rain forest regeneration. In: SHEPI-ERD, Richter. Managing the tropical forest. s. 1., Australian National University, 1985. p. 2258.

TURNER, 1. N. Tree seedling growth and survival in a Malaysian rain forest. Biotropica, 22(2): 146-54, 1990.

UHL, C.; MURPEY, P. G. Composition, structure, and regeneration of a tierra firme forest in the Amazon basin off Venezuela. Tropical Ecology, 22(2): 219-37, 1981.

VIANA, V. M. Seed dispersal and gap regeneration of tropical tree species. Cambridge-
Massachusetts, Harvard University, 1989. 270 p. Tese de Doutorado.

VIEIRA, G.; HIGUCHI, N. Efeito do tamanho de clareira na regeneração natural em floresta mecanicamente explorada na Amazônia Brasileira. In: CONGRESSO FLORESTAL BRASILEIRO, 6. 1990. Resumos. Campos do Jordão, 1990. p. 22-27.

WHITMORE, T. C. Gaps in the forest canopy. In: TOMLINSON, Zimmerman. Tropical trees as living systems. London, Cambridge Univ. Press, 1978. p. 639-55.

WHITMORE, T. C. Tropical Rain Forest of the Far East. 2 ed. Oxford, Oxford University Press, 1984. 352 p.

WHITMORE, T. C. Tropical Rain Forest dynamics and its implications for management. In: GOMESPOMPA, A.; WHITMORE,T. C.; HADLEY, M. Rain forest regeneration and management. Paris, UNESCO and The Part Eenon Publishing Group, 1990. p.67-89. 